\title{
Larinus berti sp. n. (Coleoptera, Curculionidae, Lixinae) from North Africa
}

\author{
Levent Gültekin ${ }^{1, \dagger}$, Miguel A. Alonso-Zarazaga ${ }^{2, \ddagger}$ \\ I Atatürk University, Faculty of Agriculture, Department of Plant Protection, 25240 Erzurum, Turkey 2 Depto. \\ de Biodiversidad y Biología Evolutiva, Museo Nacional de Ciencias Naturales, José Gutiérrez Abascal, 2, E-28071 \\ Madrid, Spain \\ † http://zoobank.org/BF88C4D6-CD27-46DF-AF01-C0DC8A7C5B5B \\ ¥ http://zoobank.org/EA3695DA-2C2E-4021-95CB-11D24ED253FO \\ Corresponding author: Miguel A. Alonso-Zarazaga (zarazaga@mncn.csic.es)
}

Academic editor: Lyubomir Penev | Received 7 June 2013 | Accepted 11 September 2013 | Published 14 October 2013

http://zoobank.org/E5E19E8E-B4A9-4F29-BD66-A9C8C75BC886

Citation: Gültekin L, Alonso-Zarazaga AA (2013) Larinus berti sp. n. (Coleoptera, Curculionidae, Lixinae) from North Africa. ZooKeys 342: 21-28. doi: 10.3897/zookeys.342.5754

\begin{abstract}
A new species, Larinus berti sp. n. is described from Morocco and assigned to subgenus Cryphopus Petri, 1907 (Curculionidae: Lixinae; Lixini). Diagnostic characters of the new species are large size, elongateovate body, bisulcate sub-quadrangular rostrum, triangularly raised dorsum of rostrum, flat subgena and submentum, Y-shaped apodeme of sternite VIII of female and thin nodulus of spermatheca.
\end{abstract}

\section{Keywords}

Larinus, Cryphopus, taxonomy, new species, Lixini, Curculionidae

\section{Introduction}

The weevil genus Larinus Dejean, 1821 is considered a beneficial group in the fight against invasive thistles of the tribe Cardueae (Asteraceae) (Ter-Minasian 1967; Zwölfer et al. 1971; Gültekin 2006; Gültekin et al. 2008). According to the world catalogue by Alonso-Zarazaga and Lyal (1999), this genus is divided into four subgenera: Cryphopus Petri, 1907, Larinus, Larinomesius Reitter, 1924 and Phyllonomeus Gistel, 1856. In a 
recently prepared catalogue by Gültekin and Fremuth (2013), Larinus approximately consists of 100 species in the Palaearctic Region, with its highest species richness in the Mediterranean. Five species are assigned to Cryphopus and their distribution is confined to the Western Mediterranean (Gültekin and Fremuth 2013). Its diagnostic characters are the expanded outer apical angle of the protibia and the unequal length of the tarsal claws. This paper deals with the description of a new species from this subgenus.

\section{Materials and methods}

Measurements were taken using an ocular micrometer attached to a Leica MZ75 stereo microscope and are defined as follows: body length: from anterior margin of eye to posterior margin of elytra; rostrum length: from apex of rostrum to anterior margin of eye in side view; prothorax length: from anterior margin to the posterior margin of scutellar lobe along midline. For the morphological study, dry adults were placed in lukewarm clean water overnight and their genitalia were dissected. Parts with muscles and other tissues were stored in $10 \% \mathrm{KOH}$ overnight, cleaned with distilled water and $70 \%$ ethanol. Genitalia were observed and photographed in glycerine under a stereo microscope, and kept in glycerine microvials or allowed to dry and glued onto cards under the pinned specimens from which they were dissected. Photographs were taken with a Leica DFC 420 digital camera attached to the stereo microscope using LeicaLAS software for montage. The digital images were then imported into Adobe Photoshop 8.0 and CorelDRAW X4 for labelling and plate composition.

The material examined is deposited in the following collections:

MNCN Museo Nacional de Ciencias Naturales, Madrid, Spain.

SMNH The Swedish Museum of Natural History, Stockholm, Sweden.

\section{Taxonomy}

Larinus (Cryphopus) berti Gültekin \& Alonso-Zarazaga, sp. n. http://zoobank.org/EECCA20D-0AE2-4878-8432-7ABAA9613811 http://species-id.net/wiki/Larinus_berti

Diagnosis. Larinus berti Gültekin \& Alonso-Zarazaga, sp. n. can be recognized because of its elongate-ovate large sized body (Figs 1-2), bisulcate sub-quadrangular rostrum, triangularly raised dorsum of rostrum (Fig. 3), flat subgena and submentum, Yshaped apodeme of sternite VIII of female (Fig. 14) and thin nodulus of spermatheca. The new species is related to Larinus griseus Capiomont, 1874 but the latter clearly differs in the following characters: apodeme of sternite VIII of female is not Y-shaped, the subgena of rostrum is depressed, the submentum is distinctly raised at apex, and the central keel of dorsum is tricarinate. 
Description. Measurements (in mm): Body length: 13.60-14.40. Rostrum: length 2.70-2.80, width 1.50-1.60. Prothorax: length 4.00-4.20, width 5.30-5.50. Elytra: length 9.00-9.20, width 6.30-6.80.

Body elongate-ovate (Figs 1-2).

Vestiture. Ventral and lateral surface of head, dorsum of rostrum, pronotum and elytra with very short sparse greyish piliform scales; on elytra whitish grey pubescence forming small patches especially along striae; submentum, prosternum, medial part of metasternum, legs and abdominal ventrites with somewhat longer, denser and partly suberect hair-like pubescence; coxae, sides of metasternum and ventrite I, metanepisternum, mes- and metepimeron with bifid scales; mesosternum and mesanepisternum with 4- and 5-fid scales; scales on posterior part of metanepisternum and metepimeron very dense. Apical margin of prothorax with short dense piliform scales, longer on prosternum and ocular lobes. Tibial praemucro with a tuft of setae projecting towards uncus.

Head spherical, hind ventral margin with a small notch, vertex weakly visible, frons flat in female, slightly convex in male, frontal pit small, superficial, rounded. Eyes elliptical, weakly convex, ventral half narrower than dorsal. Rostrum (Fig. 3) sub-quadrangular in section, in dorsal view parallel-sided, weakly widened at apical third, with two deep longitudinal sulci reaching apical fourth and convergent caudad, area between sulci distinctly raised, with median keel at apical third, a transversely curved ridge present immediately before epistomal area, dorsolateral margins of rostrum obtuse, rostral pit invisible in female, distinct in male on median keel, minutely and coarsely punctured (as well as forehead); in side view straight. Scrobes with ventral margin partly visible dorsally. Antenna (Fig. 4) inserted about $0.30 \times$ from apex of rostrum in male, $0.40 \times$ in female. Scape slightly shorter than funicle, dorsoventrally depressed, weakly curved at middle, abruptly widened at apex, wider than desmomere 1, desmomeres 1-2 subconical, desmomere 1 about $1.30 \times$ as long as desmomere 2, desmomere 3 short, subisodiametric, about $0.65 \times$ as long as desmomere 2 , desmomeres 4-7 gradually widening, desmomere 7 widest; club moderately elongate with acute apex, about $1.70 \times$ as long as wide.

Prothorax in dorsal view sub-trapezoidal, base moderately and triangularly arched towards scutellum, lateral margins of prothorax gradually and gently converging from base to apical half, rather strongly rounded apicad of it and then abruptly constricted in a short collar at apical $1 / 6$; anterior margin very gently emarginate on dorsal part, evenly curved towards slightly developed postocular lobes; prosternum with anterior margin moderately emarginate. Pronotal surface convex, with dense, minute punctures, somewhat larger punctures scattered sparsely and partly confluent on prescutellar area.

Scutellum small and not clearly visible.

Elytra subparallel-sided in basal $2 / 3$, gradually and roundly narrowed towards apex, constricted before mid-length; humeral calli moderately developed, preapical prominences distinct and located at end of intervals 4-7; interstriae flat, subequal in width on disc, narrower caudad, about $5 \times$ as wide as a stria on disc, interstria 10 wider than others in basal third, interstria 11 sinuate, weakly curved towards metanepister- 

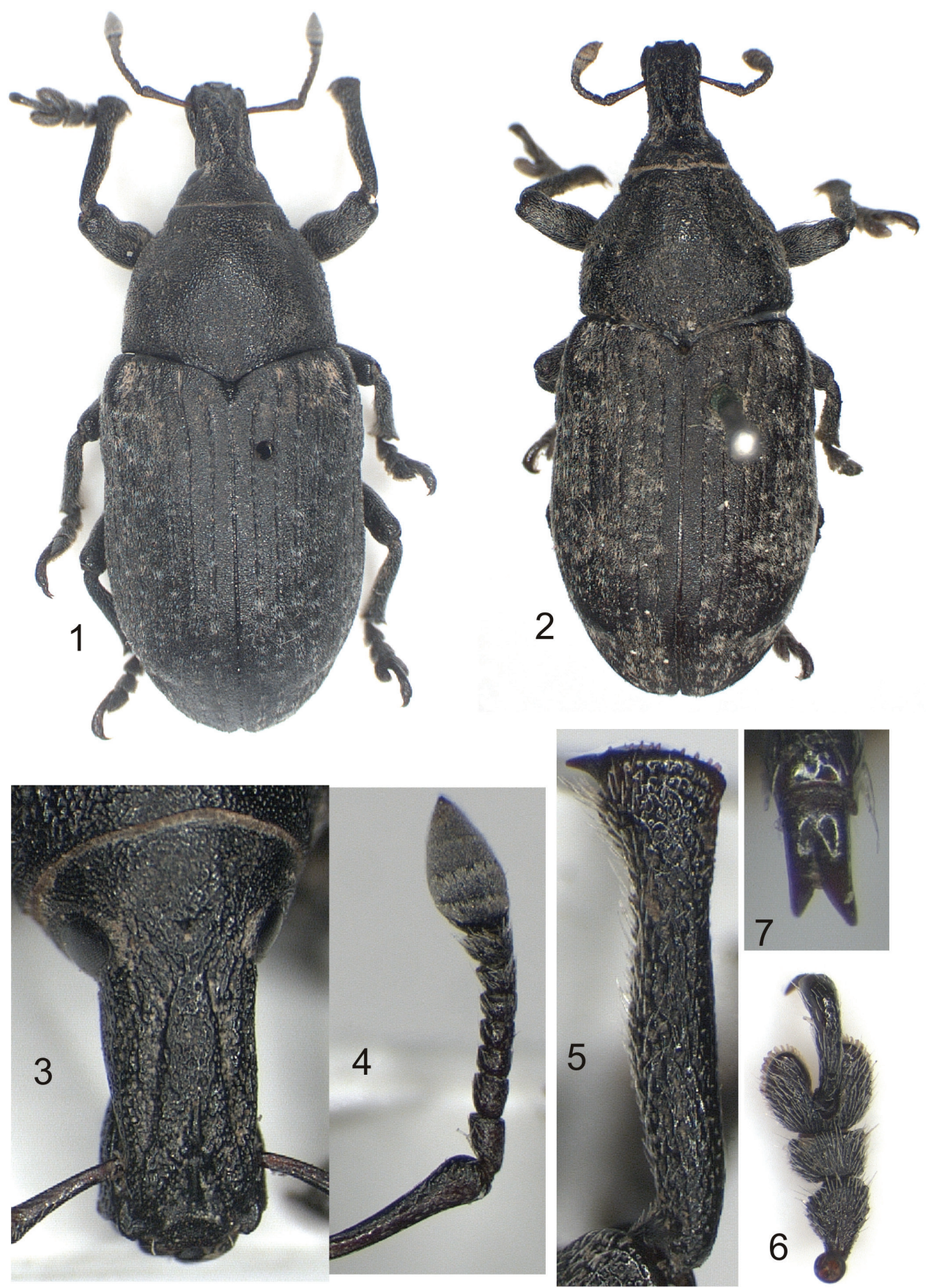

Figures I-7. Larinus berti sp. n.: I holotypus (male) $\mathbf{2}$ paratypus (female) $\mathbf{3}$ rostrum (male) $\mathbf{4}$ antenna (male) $\mathbf{5}$ protibia (male) $\mathbf{6}$ protarsus (male) $\mathbf{7}$ claws. 
num; striae mostly formed by rounded and separate punctures, these partly confluent along basal part and on posterior declivity, stria 10 sinuate and deeply sulciform.

Abdomen with ventrites 3 and 4 in male, and 3 only in female medially depressed.

Legs. Femora edentate, medially swollen, narrower than rostrum. Outer margin of protibia slightly, inner margin distinctly sinuate, apical part dilated outwards, about twice as wide as base, apex weakly curved, inner margin in male obtusely serrate, in female 3-4 small denticles present at apical half, serrate in basal half, denticles closest to uncus slightly larger than others (Fig. 5). Inner margins of meso- and metatibia nearly straight, outer margin slightly sinuate, mesotibia with 2-3 denticles, metatibia serrate in both sexes. Uncus sharp, moderately sized, gradually smaller from pro- to metatibia. Apical comb of spines short on protibia (longer on meso- and metatibia), bases of spines partly connate. Tarsi (Fig. 6) wide, tarsomere $31.40 \times$ as wide as tarsomere 2, 1.25x as wide as long, solea complete. Onychium stout, curved, gradually widened from base to apex, $0.65 \times$ as long as total length of tarsomeres 1-3; claws connate at basal third, of unequal length, inner claw shorter than outer, moderately divergent in apical half (Fig. 7).

Male terminalia and genitalia. Penis in dorsal view stout, elongate, gradually narrowing from base to apical fourth, constricted in this part and narrowing again towards apex (Figs 8-9), incompletely sclerotized medially from basal third to ostium; apical plate triangular, $0.75 \times$ as long as wide; in lateral view, penis strongly curved at basal third, apical fourth almost straight (Fig. 10). Tegmen forming a ring with short ventral apodeme, parameroid lobes absent. Spiculum gastrale thin, stick-shaped, curved outwards, slightly shorter than penis (Fig. 11). Sternite VIII forming a single plate (Fig. 12), well sclerotized, apical margin with sparse, short setae.

Female terminalia and genitalia. Tergite VIII semicircular (Fig. 13), posterior margin with a dense row of hairs. Sternite VIII with lamina transversely oval, prolonged cephalad in an apodeme bifid at apex (Fig. 14); lateral arms wide, angularly arched outwards; margin angularly emarginate with a small medial triangular notch. Coxite well sclerotized, narrowed to apex, stylar base conical, stylus cylindrical, slightly longer than base (Fig. 15). Spermatheca nearly C-shaped, ramus well developed, distinctly wider than nodulus, the latter thin and cylindrical with a small tubercle at inner apical part, apex of cornu obtuse, gland well developed, subspherical (Fig. 16).

Variation. Size variation is presented above under the Measurements section. A detailed variation cannot be presented because there are only two specimens available, and no further specimens have been traced in the rich Moroccan collections of the MNHN (Paris) and MNCN (Madrid). The female specimen shows a partly worn out vestiture, especially on elytra.

Type material. Holotype (male) (Fig. 1), MOROCCO, Mischliffen, Md. Atlas, Marruecos, 2000 m, 5.VII.1988, Fdz-Rubio leg. [MNCN, Madrid]. Paratype (female) (Fig. 2), Afrique varia, “4”, [Chevrolat Coll.] [SMNH, Stockholm].

Etymology. The new species is named after our good friend Bert Viklund (The Swedish Museum of Natural History, Stockholm). 

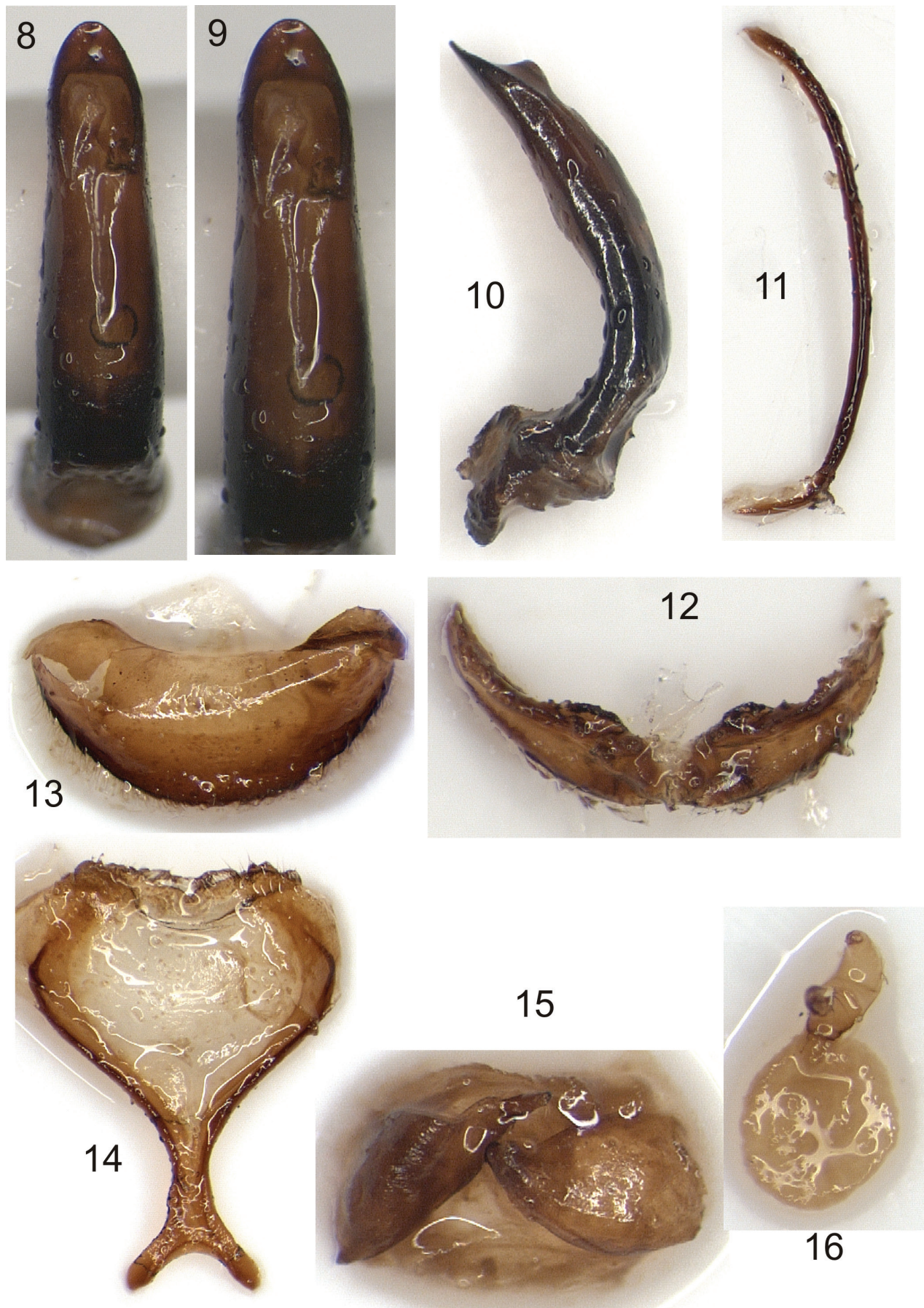

Figures 8-16. Terminalia and genitalia of Larinus berti sp. n. (8-12 male; | 3-16 female): 8-9 dorsal view of penis $\mathbf{I} \mathbf{0}$ lateral view of penis I I spiculum gastrale $\mathbf{I} \mathbf{2}$ sternite VIII $\mathbf{3}$ tergite VIII I $\mathbf{4}$ sternite VIII I $\mathbf{5}$ coxite $\mathbf{I} \mathbf{6}$ spermatheca. 


\section{Key to the species of subgenus Cryphopus}

The known species of the subgenus Cryphopus can be separated as follows:

1 Body broadly ovate. Protibia strongly widened outwards, outer margin strongly sinuate. Claws strongly unequal in length.....................................2

- Body elongate-ovate. Protibia moderately widened outwards at apex, outer margin nearly straight. Claws moderately unequal in length ........................4

2 Length more than $15 \mathrm{~mm}$. Apex of protibia hammer-shaped

L. bombycinus Lucas, 1847

- $\quad$ Length less than $8 \mathrm{~mm}$. Apex of protibia not hammer-shaped .....................3

3 Protibia with uncus and praemucro well separated

L. ferrugatus Gyllenhal, 1835

- $\quad$ Protibia with uncus and praemucro tangent...L. maroccanus Capiomont, 1874

4 Subgena and apex of submentum flat. Apodeme of female sternite VIII bifid at apex ................................... L. berti Gültekin \& Alonso-Zarazaga, sp. n.

- $\quad$ Subgena depressed, apex of submentum strongly raised. Apodeme of female sternite VIII simple 5

5 Rostrum in dorsal view subparallel-sided, thick, $1.25 \times$ as wide as maximum width of profemora, with a thin median keel ... L. reichei Capiomont, 1874

- $\quad$ Rostrum in dorsal view compressed at middle, ca. as wide as maximum width of profemora, with a thick median keel and two deep sulci

.L. griseus Capiomont, 1874

\section{Acknowledgements}

We thank our colleagues Bert Viklund and Kjell Arne Johanson (The Swedish Museum of Natural History, Stockholm) for their help during the first author's visit. The study was supported by grants from the European Commission's (FP 6) Integrated Infrastructure Initiative programme SYNTHESYS (ES-TAF, SE-TAF). The English language has been revised by a professional editor.

\section{References}

Alonso-Zarazaga MA, Lyal CHC (1999) A world catalogue of families and genera of Curculionoidea (Insecta: Coleoptera) (excepting Scolytidae and Platypodidae). Entomopraxis, Barcelona, 315 pp.

Gültekin L (2006) Seasonal occurrence and biology of globe thistle capitulum weevil Larinus onopordi (F.) (Coleoptera: Curculionidae) in northeastern Turkey. Munis Entomology and Zoology 1: 191-198. 
Gültekin L, Cristofaro M, Tronci C, Smith L (2008) Natural history studies for the preliminary evaluation of a prospective biological control agent of yellow starthistle, Larinus filiformis (Coleoptera: Curculionidae). Environmental Entomology 37: 1185-1199. doi: 10.1603/0046-225X(2008)37[1185:NHSFTP]2.0.CO;2

Gültekin L, Fremuth J (2013) Lixini. In: Löbl I, Smetana A (Eds) Catalogue of Palaearctic Coleoptera. Vol. 8. Brill, Leiden, 456-572.

Ter-Minasian ME (1967) Žuki-dolgonosiki podsemejstva Cleoninae fauny SSSR. Cvetožily i stebleedy (triba Lixini). Nauka, Leningrad, 140 [+ 1 unnumbered] pp.

Zwölfer H, Frick KE, Andres LA (1971) A study of the host plant relationships of European members of the genus Larinus (Col.: Curculionidae). Technical Bulletin of the Commonwealth Institute for Biological Control 14: 97-143. 